\title{
THE PATHOGENESIS OF VALVULAR THICKENING IN RHEUMATIC HEART DISEASE
}

\author{
BY \\ P. S. TWEEDY \\ From the Royal Victoria Infirmary, Newcastle upon Tyne \\ Received May 22, 1955
}

Recently Magarey $(1949,1951)$ has shown the part played by repeated fibrin deposition in the pathogenesis of valvular thickening in rheumatic heart disease. He showed that fibrin deposited on the surface of a thickened valve became hyalinized, lost its fibrin-staining qualities, and became covered over by endothelium on which further fibrin might be deposited before the first was organized to fibro-cellular tissue. As many as three layers of fibrin in varying stages of organization were described. By implication (though not explicitly) he suggests that buried hyaline material in valves is usually or always buried fibrin, though he does not specifically discuss the question of how to decide whether buried homogenous acidophil material is altered fibrin or a degenerative change in underlying collagen. He dealt with changes in the chronic stages of the disease and did not consider at length the part played by vegetations in acute rheumatic valvulitis or the changes preceding thrombus deposition. It is the purpose of this communication to suggest that all such collections of homogeneous acidophil material found in rheumatic valves are organizing or incompletely organized thrombotic deposits and that there is no compelling histological evidence that they are ever degenerated swollen collagen or a ground substance change. A further conclusion is that the myxomatous swelling associated with fibroblastic proliferation that is seen in acute rheumatic valvulitis is not a precursor of so called fibrinoid degeneration but a result of rapid organization of thrombus. In addition, Magarey's views on the importance of thrombus deposition in the thickening of valves and in the stenosis of valve ostia are confirmed and extended to include the stage of acute valvulitis. During the study particular attention was paid to the lesions preceding thrombus deposition.

Pathogenesis of Valve Thickening. The commonly accepted view of the pathogenesis of the thickening of valve cusps is that it is due to an acute valvulitis often, but not necessarily, with inflammatory cell infiltration, œdema, degeneration of collagen, marked fibroblastic proliferation, and subsequent cicatrization. Koniger (1903) emphasized the presence of marked swelling of subendothelial connective tissues which had undergone a "homogenizing hyaline necrosis" (called by Klinge, (1933) "fibrinoid degeneration"). Coombs (1911, 1924) stressed the part played by submiliary nodules which he identified with those described by Aschoff and Tawara (1906).

In addition to the above-mentioned writers, Gross and Friedberg (1936), Wilson (1940), and Murphy (1952), hold similar views. Gross and Friedberg (1936a) also emphasize the part played by the incorporation of chordæ tendineæ into the valve cusps and mutual fusion of the chordæ and of cusps at the commissures, which is also mentioned by Rokitansky (1852), Rindfleisch (1872), Wilson (1940), and Brock (1952). Coombs denies that this happens in the case of the mitral valve, but allows that it occurs in the aortic valve. Magarey's views have been described; he points out that deposits lead to the fusion of chordæ to the distal surface of valve cusps with resultant secondary shortening of the chordæ. Brock (1952) suggests that mutual fusion of mitral cusps takes place at certain critical sites and that it does not occur progressively from the periphery towards the centre.

The Nature of the Lesion preceding Thrombus Deposition. Veraguth (1895) states that thrombus 
deposition may occur when endothelial damage is the sole lesion or at the same time as inflammatory changes in the valve. The characteristic lesion of rheumatic endocarditis according to Koniger (1903) is deep homogenizing necrosis with œdema of the endocardium, precipitation of fibrin-like masses in the deeper layers of the subendothelium, and marked swelling which may project above the level of the endocardial surface; on this thrombus deposition may occur : leucocytic infiltration is not striking but proliferation of cells is.

Klinge's (1933) description is similar to Koniger's; he describes Aschoff nodes in the valve but does not indicate whether their occurrence is particularly associated with vegetation formation or not. Coombs $(1909,1924)$ describes a valvulitis and submiliary nodules which are groups or zones of large fibroblasts with some giant cells in a groundwork of fibrin; the fibrin is difficult to see in the myocardium, but in the endocardium there is often a central area consisting of nothing but fibrin with a sharp margin. He suggests that the nodules may sometimes be formed by necrosis of the endothelium of a newly formed blood vessel with thrombosis therein and marked peri-vascular proliferation of fibroblasts. Although he equates these nodules with those described by Aschoff and Tawara (1906) these latter authors do not refer to the presence of fibrin. Judging from the illustrations Coombs seems to be describing two kinds of nodules, viz. Aschoff nodes (in which fibrin is very rarely present) and some other form of nodule forming round fibrin or fibrin-like material such as that described by Koniger or Klinge. Veraguth, in talking of acute endocarditis mentions that if superficial organization of a vegetation occurs the most superficial layer of the cusp appears undermined by the thrombus or raised up by it. Almost complete organization of such a thrombus would look like those of Coombs' submiliary nodules which contain a well-defined area of fibrin or like the deep homogenizing (fibrinoid) necrosis of Koniger and Klinge.

Leary (1932) and Gross and Friedberg (1936) believe that superficial degeneration of cells is the lesion that precedes vegetation formation, while the latter agree with Klinge that acidophil swelling of collagen precedes fibrin deposition.

\section{The Nature and Structure of Vegetations}

These have been variously described as consisting of fibrin, fibrin and platelets, platelets only, connective tissue or a mixture of these elements (Veraguth, 1895; Coombs, 1924; Clawson, 1926; Grant and Wood, 1928; Murphy, 1952). Swollen acidophil collagen is a further constituent according to Koniger (1903), Klinge (1933), Bulloch (1906), and Gross and Friedberg (1936); it is usually said to be deep to the thrombotic element. Swift (1925) thinks that vegetations may be formed by submiliary nodules ulcerating through the endothelium.

\section{MATERIAL AND MeTHOdS}

Twenty-nine hearts with rheumatic mitral valve disease were examined, of which 26 showed marked or gross valvular deformity. One showed only moderate thickening of the cusps without gross deformity or narrowing of the valvular orifice; the myocardium contained Aschoff bodies and death was due to acute pulmonary œdema. Two were cases of acute rheumatic pancarditis in children aged 8 and 9 respectively with Aschoff bodies in the myocardium. Thickened aortic valves were examined in five of the chronic cases and so were moderately thickened mitral valves present in two hearts with calcific aortic stenosis: these valves were vascularized and although Koletsky (1946) claims that all vascularized mitral valves are due to rheumatism, there was no unequivocal evidence of rheumatism (Aschoff nodes) present in the six blocks of the myocardium examined from each of these hearts.

The incidence and nature of surface deposits on these valves was determined by examining them with a hand lens, and with a binocular dissecting microscope. Frozen sections of suspicious areas (taken at random intervals) were then cut and stained with hæmatoxylin and Sudan 3, hæmatoxylin and eosin, orcein elastic stain, and Mallory's phosphotungstic acid hæmatoxylin (M.P.A.H.). Toluidine blue 1 per cent was used on selected sections. Frozen sections were used as these showed up the texture of tissues better than paraffin embedded ones. Contiguous blocks were embedded in paraffin and stained with similar stains (except Sudan), picro Mallory, and Weigert, elastica and Gram. Selected sections were stained with Foot's reticulin stain, Weigert's fibrin stain and periodic acid Schiff (P.A.S.). Other affected valves were examined in the same way, but no effort was made to discover the absolute incidence of deposits which were found in 29 out of 31 mitral valves and four out of five aortic valves. Buried Lambl's excrescences were seen in nine cases. 


\section{SITES OF DEPOSITS}

They were found most commonly in the commissures between thickened cusps on the contact line of the valve and on the extreme tip; they were less commonly found on other parts of the proximal surface of the cusp, on the chordæ tendineæ especially near the insertion of those of the first order and in the pockets between chordæ and cusp. They lead to thickening and fusing of chordæ which then become part of the valve cusp and lengthen it. This phenomenon leads to a change in the contact line of the valve which moves distally as and if the valve so lengthens so that new generations of vegetations are laid down on a different site (see Gross and Friedberg, 1936). Fig. 1 shows a vegetation at the point of insertion of two chordæ into the cusp of a tricuspid valve; Fig. 2 is a

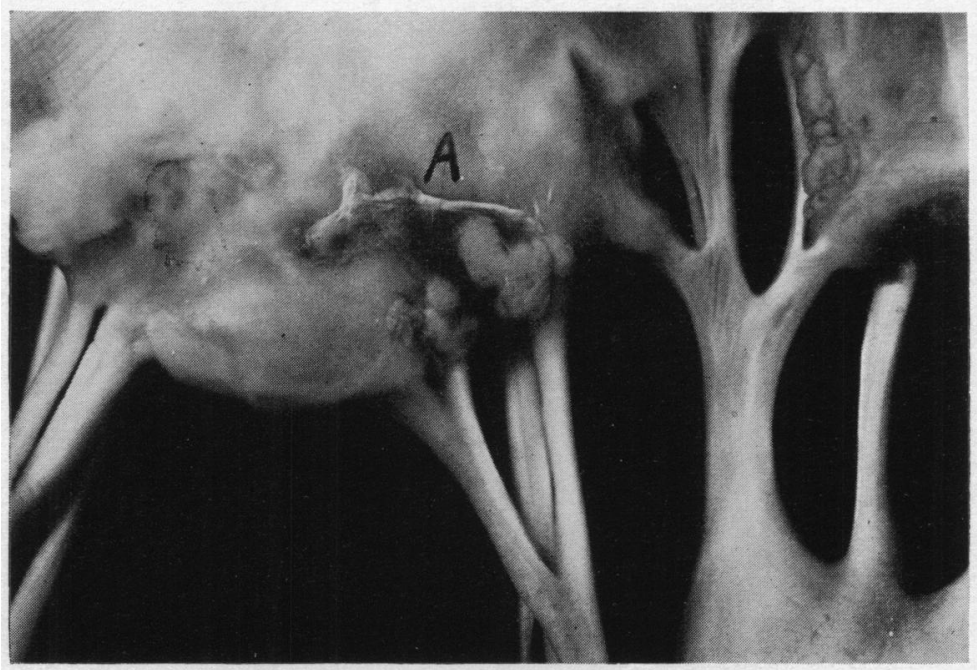

Fig. 1.-Tricuspid valve cusp, showing vegetations overlapping chorda insertions (A). $\times 5.5$.

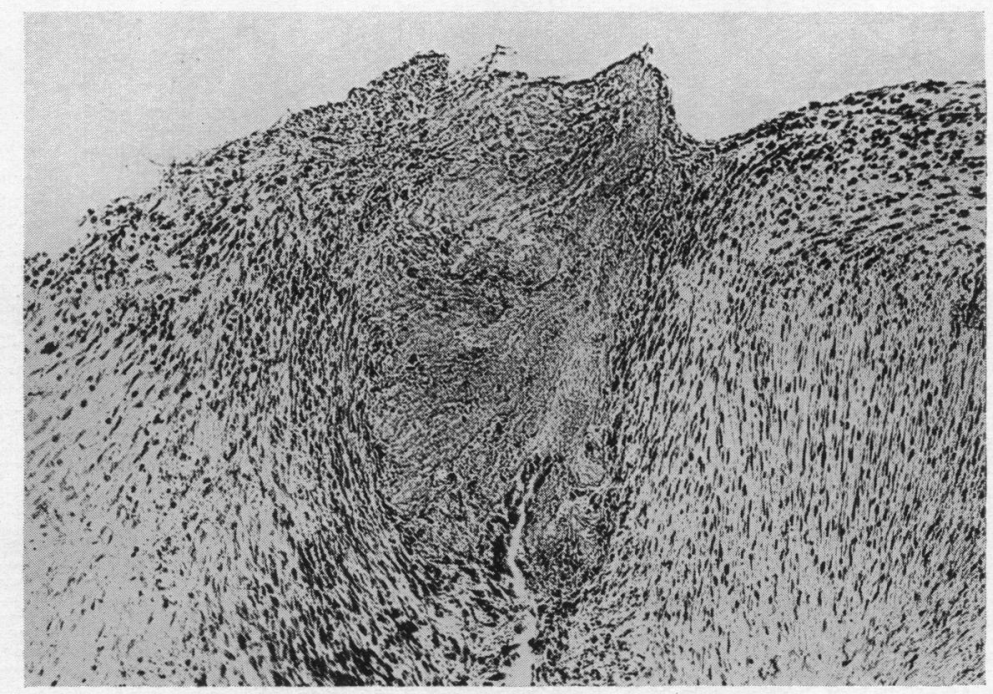

Fig. 2.-Frozen section through A of Fig. 1, showing fusion of chordæ by vegetation material. (Hæmatoxylin) $\times 100$. 
section taken through a line through A showing fusion of the chordæ by vegetation material. Fig. 1 shows them to be fused more distally also. When chordæ are inserted obliquely into the cusp as they are near the centre of both mitral cusps, their fusion together adds to the length of the cusp, the free edge of which may be made up of chordæ tendineæ.

In a case of acute rheumatic pancarditis deposited material was widespread on both surfaces of a mitral cusp and formed 5-10 per cent of the thickness of the cusp in some places.

Material deposited in the angles between the cusps (Fig. 4 and 9) and on the endothelial folds at that site in the mitral valve leads to gradual fusion of opposing cusps, mainly by a silting up process. At the same time fusion of the chordæ at these sites occurs and helps to prevent the cusps opening fully in auricular systole. In those valves that show the earlier stages of mitral stenosis, no evidence was found that fusion occurs first at certain critical points distant from the angles between the cusps, as suggested by Brock (1952).

\section{The Structure of Vegetations and of the Tissue Underlying Them}

Fig. 3 is a hæmatoxylin-stained section of a typical warty vegetation. There is recent fibrillary deposition on the surface, the layers deep to this are somewhat granular, and below that again they are homogenous. Lamination is clearly shown as is progressive organization from the base. The

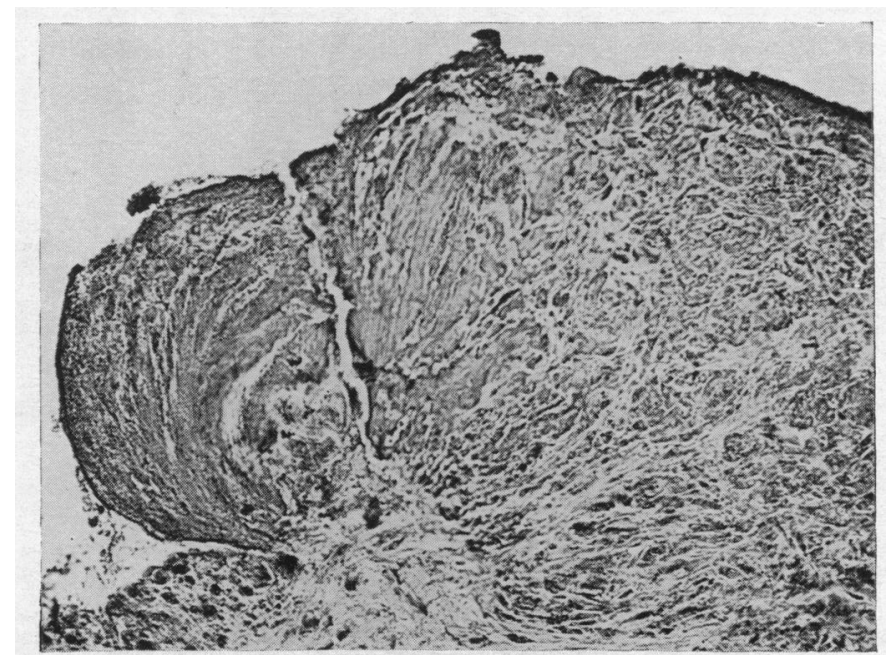

FIG. 3.-Frozen section of warty vegetation on aortic valve. It shows layering of older deposited material and the granular appearance of the most recent deposit (Hæmatoxylin and Sudan 3) $\times 140$.

material of the vegetation is acidophil (in hæmatoxylin- and eosin-stained sections) and stains partly fibrin positive and partly fibrin negative. Magarey suggests that deposits are entirely of fibrin, but in very recently deposited material there are two elements discernible, viz. a granular fibrin negative portion and a fibrillary fibrin positive one, fibrin itself. Mallory's phosphotungstic acid hæmatoxylin (M.P.A.H.) gives the most consistent reaction. As homogenization takes place, with the increasing age of the deposit, these two differently staining elements are still visible. The fibrin negative portion predominates in vegetations, especially those which are acute, the fibrin positive portion in ordinary mural thrombi and sometimes in the deposits on valves with much collagen. The staining reactions of vegetations vis à vis fibrin were felt to be explicable on the basis that there were two different constituents. The granular material is usually considered to consist of platelets, though there seems to be no absolute unequivocal evidence that this is so. Zucker (1949) gives a discussion of the part played by platelets in thrombosis. 
To compare with Fig. 3, Fig. 4 is a frozen section stained with hæmatoxylin of the commissure of a mitral valve; Fig. 5 is a hæmatoxylin- and eosin-stained section from the same block after it had been embedded in paraffin. Some granular superficial deposit can be seen in both of these sections which also demonstrate the difference between the texture of frozen and paraffin sections

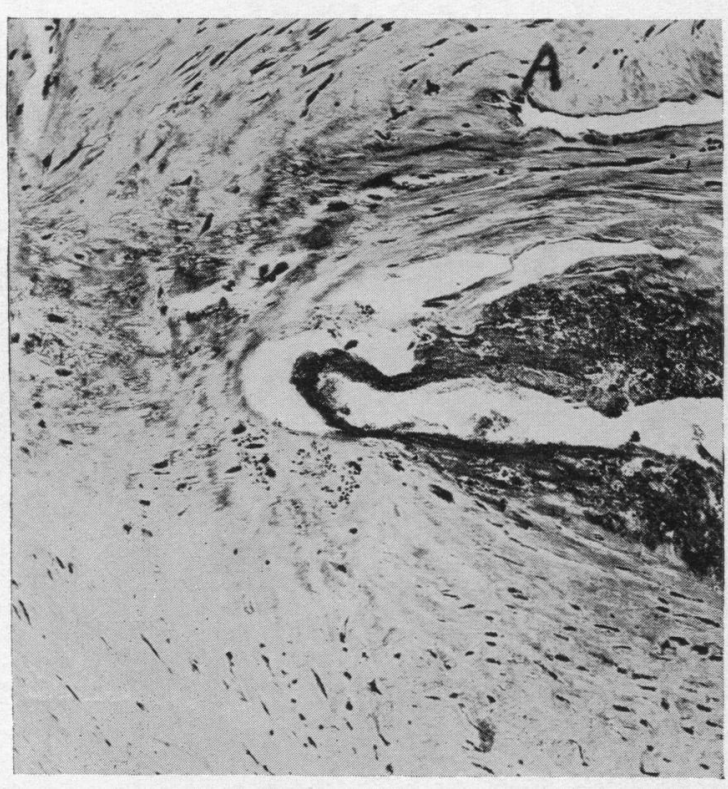

FIG. 4.-Deposit in a commissure of the mitral valve. Frozen section. (Hæmatoxylin and Sudan 3) $\times 90$.

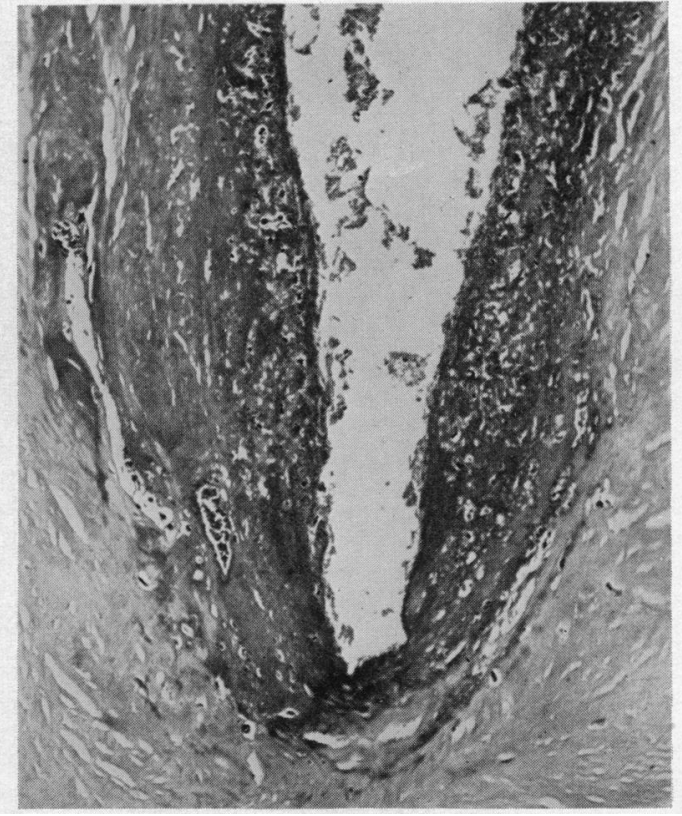

Fig. 5.-A neighbouring section to that shown in Fig. 4 -paraffin embedded. (Hæmatoxylin and Eosin) $\times 90$.

so stressed by Duguid (1952). These sections pose the problem of the nature of homogenous eosinophilic material often seen on the surface of valves or underlying the frankly thrombotic part of a vegetation. Some of the other writers who have been quoted believe that when this material is seen in deeper layers of the valve or in the base of a vegetation it is swollen degenerated collagen staining like fibrin (e.g. Koniger, 1903; Klinge, 1933; Coombs, 1924; Gross, 1936). An effort was made to decide whether such material was purely thrombotic (made up of fibrin and some other constituent, probably platelets), purely degenerative, or a mixture of the two. The latter view would follow from any hypothesis that accepted the occurrence of fibrinoid degeneration. It was found that in that part of the cusp away from the commissure this material never lay immediately deep to an intact superficial elastic lamina or even deep to coarse broken fragments of elastica where it might be expected to occur were it due to degeneration of deep tissues. Its occurrence deep to an elastic lamina in the region of the commissures cannot be held to be due necessarily to degeneration because of the large number of folds and pockets in these situations. In Fig. 4, for instance, there is an endothelial-lined cleft at A; if thrombosis occurred in this it might at first sight look as though it were deep degeneration. Thrombi were seen in pockets deep to elastic laminæ.

Another fact that makes it difficult to assess whether a lesion is a deep degeneration or a buried thrombus is the rapidity with which a thrombus may become covered by endothelium or even by a fibroblastic layer, as shown by Duguid (1952). Fig. 6 is a hæmatoxylin-stained frozen section from a valve showing active valvulitis with many Aschoff nodes; this shows endothelium growing over very recent deposit below which two further layers are distinguishable. From above downwards 


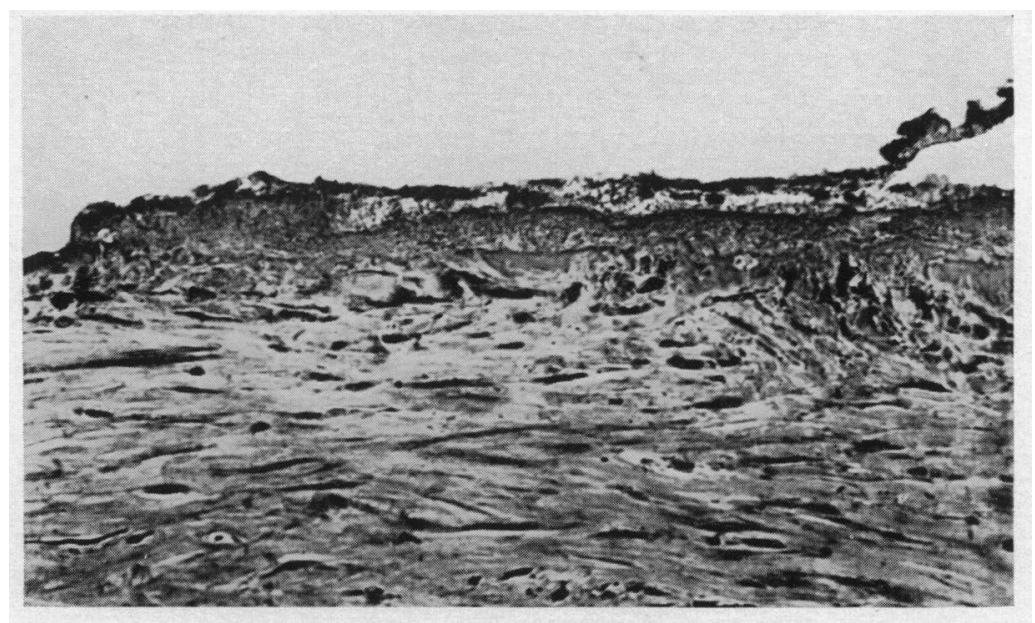

FIG. 6.-Layering of deposit on the surface of mitral valve, with overgrowing endothelium. Frozen section. (Hæmatoxylin) $\times 200$.

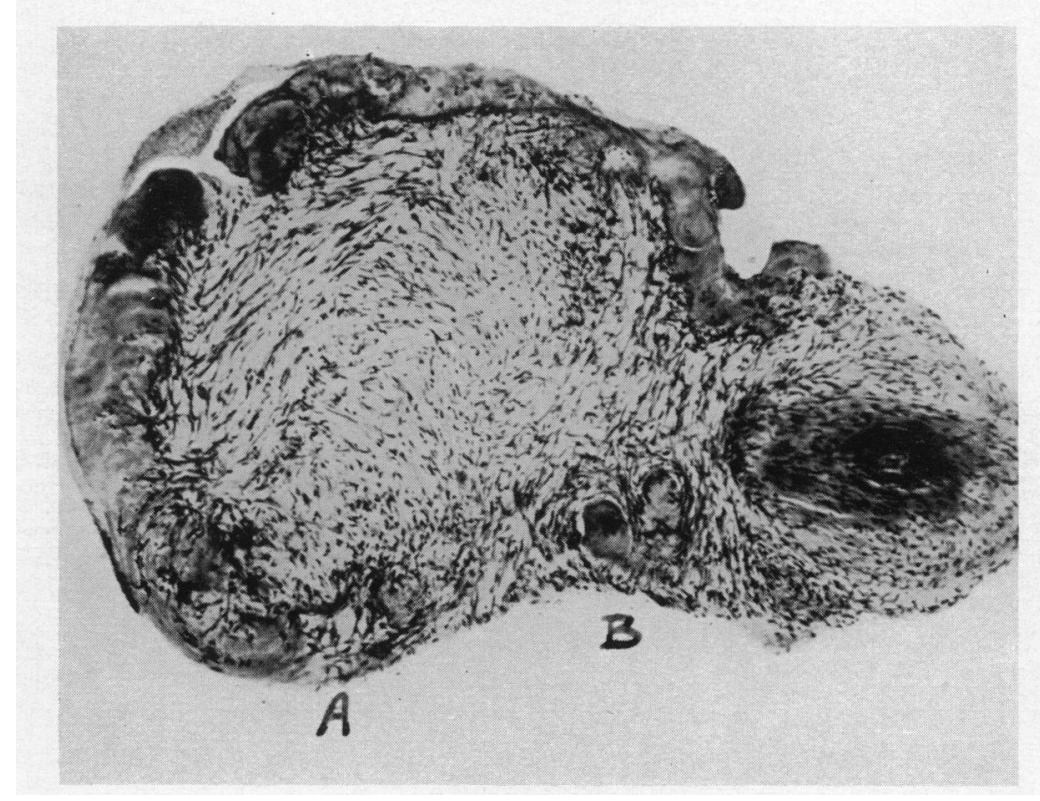

FIG. 7.-Chorda tendinea (seen on the right of the figure) and a vegetation showing surface deposit and overgrowing fibroblasts (A and B). Frozen section. (Mallory's phosphotungstic acid hæmatoxylin) $\times 55$.

the layers show a change from a partially fibrillary loose textured appearance to a homogeneous hyaline one. These are the changes shown by ageing thrombus. It would be difficult to explain them on the basis of degeneration of subendothelial connective tissue. In neighbouring sections further from the edge of the lesion, endothelium was not yet present. Fig. 7 is a frozen section, stained with M.P.A.H. of a vegetation on a chorda tendinea. The portion on the right is the obliquely cut chorda, the rest organizing vegetation. At $\mathrm{A}$ it can be seen how fibroblasts tend to 
grow over lesions, while at $\mathrm{B}$ are two areas of buried thrombus, which have the appearance described by Coombs as those of submiliary nodules in the endocardium.

In lesions such as that shown in Fig. 4 and 5 one wants to know whether the superficial layer of acidophil material is all thrombus, all degenerated collagen, or a mixture. The paraffin section, Fig. 5, gives an appearance that might be interpreted as a degenerative lesion in connective tissue, together with a certain amount of recent superficial granular deposit. On the other hand, in the frozen section (Fig. 4) the surface material seems to be quite clearly defined from the underlying tissue and certainly gives the impression of being superimposed on it. Lamination is just visible towards the apex of the commissure, but it is more clearly shown in Fig. 8, a higher powered view

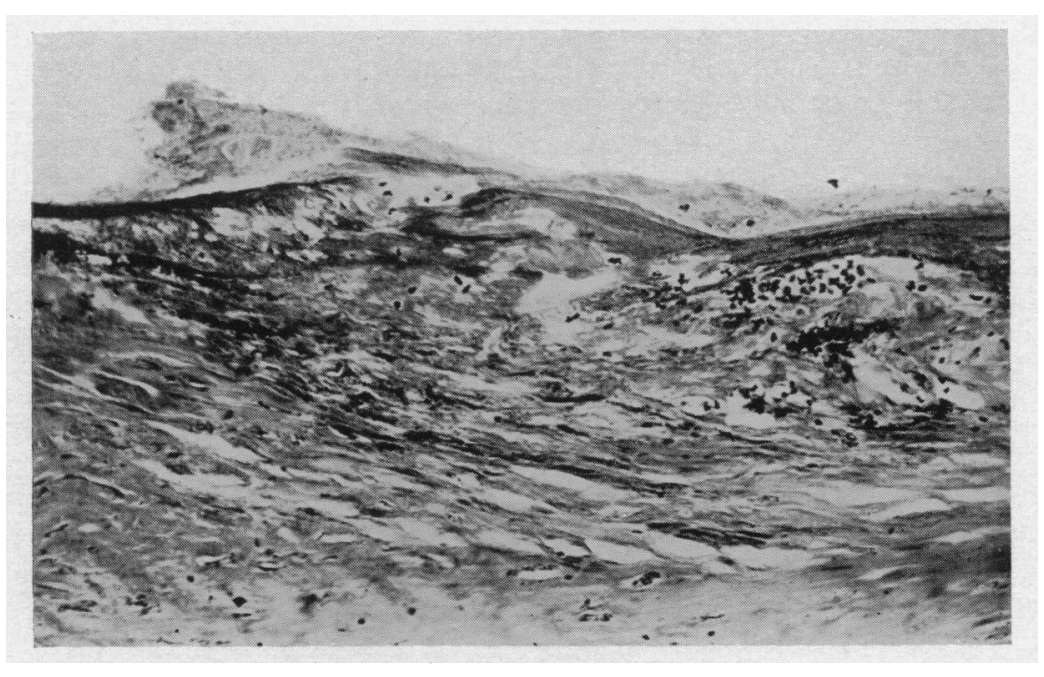

FIG. 8.-Neighbouring portion of valve shown in Fig. 4 and 5. Frozen section. (Mallory's phosphotungstic acid hæmatoxylin) $\times 160$.

of a neighbouring part of the same section. This also shows more clearly the granular or amorphous fibrin-negative material deposited on the surface, organization from below with areas of fibrin staining material in the deeper layers of the valve, and entrapped groups of red cells clumped together. Both show the fibrinoid and non-fibrinoid reactions of vegetation thrombus. The presence of surface deposit, of lamination, and of entrapped red cells below the surface, which may all occur in typical verrucæ, suggests that successive layers of thrombus are laid down one on the other to form this acidophil layer. On this hypothesis it is easy to explain the underlying patches of fibrinoid or partially fibrinoid material which occur in Fig. 8; they are buried thrombus not yet organized; it is unnecessary to postulate any degenerative change to explain the appearances. These patches of deeper homogenous material are P.A.S. positive, a staining reaction that occurs in ageing thrombus. Is it reasonable to suppose that thrombi can be buried far below the surface without becoming converted into connective tissue? In Fig. 8 it can be seen that organization is being carried out by relatively few cells and that a dense collagenous tissue is being formed. This paucity of cells might well explain the presence of deeply buried thrombus such as the deeply staining material in the top, left-hand corner of Fig. 4; as organization appears to be more rapid and complete when cells are plentiful there is no compelling reason to suppose that such tissue is degenerative rather than "buried" once it is accepted that incomplete organization of successive layers of deposited thrombus will give such an appearance. That the burying effect occurs in more acute lesions has been shown in Fig. 7.

The presence of metachromasia in such myxomatous-looking tissue as is shown in this figure has been held to be a pre-fibrinoid degeneration change (Altshuler and Angevine, 1949), but this is also 
found in recently formed tissue as shown by Tamayo and Ihnen (1953), who demonstrated its presence in healing wounds. In this study it was also found in organizing verrucæ; neither this nor the presence of a myxomatous appearance is of any value in distinguishing between degeneration and recent formation. The same remarks apply to the presence of fine elastica fragments which are held by Gross and Friedberg (1936) to indicate degenerative changes; an indistinguishable appearance is found in organizing mural thrombi, and P.A.S. positive tissue may also be present in such situation. The cellularity of a lesion was not a reliable guide as to whether it was degenerative or organizing because in acellular portions of the heart organization is carried out by very few cells, and relatively hyaline acellular tissue may be formed, The occurrence of necrotic changes in cells bore no constant relationship to acidophil homogeneous material.

In view of Coombs' description of submiliary nodules, a comparison of Aschoff nodes and valve lesions was carried out in order to see if this shed any light on the nature of deeply buried acidophil tissue. It is reasonable to suppose that in rheumatic heart disease the fundamental lesion in the connective tissue of the myocardium is the same as that in the valve; Coombs, for instance, describes submiliary nodules in the myocardium and in the endocardium. If myocardium and valve lesions are identical there should be comparable changes in valve cusp and myocardium. Aschoff nodes were present in 12 of 23 hearts examined for them; fibrin staining material was only very rarely seen and then it was fragmentary in character and never took the form of clearly defined areas of acidophil material. Many of the myocardial Aschoff nodes contained myocardial fibres in various stages of degeneration and it was difficult sometimes to distinguish these from fibrin. In the Aschoff nodes seen in valves, collagen fibres appeared to be swollen and fragmented in the frozen and paraffin sections, but they never showed the texture or staining reactions of vegetation material, they never stained like fibrin, and they were not associated with areas of clearly defined swollen acidophil material. It therefore appears doubtful whether the homogeneous acidophil lesions deep in a rheumatic valve can be the same sort of lesion as that which forms the basis of the Aschoff node. The former can all be explained as thrombi which have been incorporated into the valve; the latter is a cellular reaction to some form of tissue damage.

In many recent vegetations the base is formed by recently organized fibrous or fibro-elastic material (as in Fig. 4 and 8 ) in which the cells may be relatively scanty. This may occasionally give rise to the presence of collagen fibres ending blindly in the vegetation material; this does not necessarily indicate that the vegetation consists of degenerated collagen (Allen and Sirota, 1944). It is more probably due to incomplete organization such as would occur if there were too few cells present or if there was slow necrosis of the organizing cells. In organizing lesions some of the fibroblasts may show pyknosis which is not accompanied by anything suggestive of "fibrinoid" degeneration. As is well known, necrosis may also affect the endothelium growing over the surface of thrombus, as well as normal endothelium. In a relatively acellular area cell death may lead to marked slowing of organization giving the appearance shown in Fig. 9. This sort of lesion (called by Allen and Sirota "degenerative verrucal endocardiosis") is relatively common in old thickened valves though it may occur alongside more cellular lesions. The texture and staining reactions of these vegetations seem to be the same as those of vegetations which are more cellular. This one shows the lamination that is present in acute warty vegetations. It seems unnecessary to postulate that some of these vegetations are due to degenerated swollen collagen and others due to thrombotic deposits as do Allen and Sirota (1944) and Gross and Friedberg (1936). If organization (i.e. conversion of fibrin to collagen) were slow or non-existent, a thrombotic type of vegetation would eventually look like the type they call degenerative. The thin, deeply acidophil hyaline strips which occur on the surface of a valve can be explained by the same mechanism of incomplete, delayed or even absent organization. Barnard (1953) has shown that artificially produced fibrin emboli may be incorporated into the wall of a pulmonary artery and remain unorganized for a time even when cells are plentiful. He also shows that the elastica lamina deep to these fibrin emboli becomes fragmented, so that if such an appearance is found deep to deposit on a valve cusp, it does not necessarily mean that degeneration has preceded the deposition. 


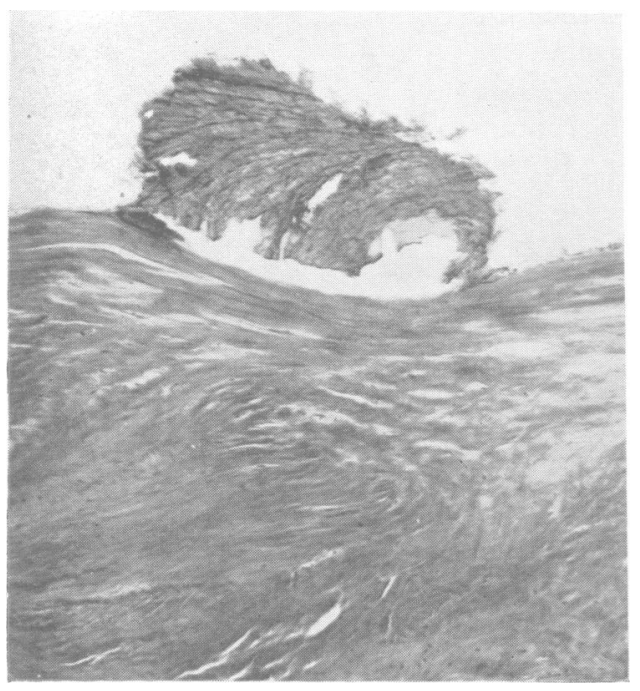

FIG. 9.-Mitral valve with acellular hyalinized vegetation. Frozen section. (Mallory's phosphotungstic acid hæmatoxylin) $\times 55$.

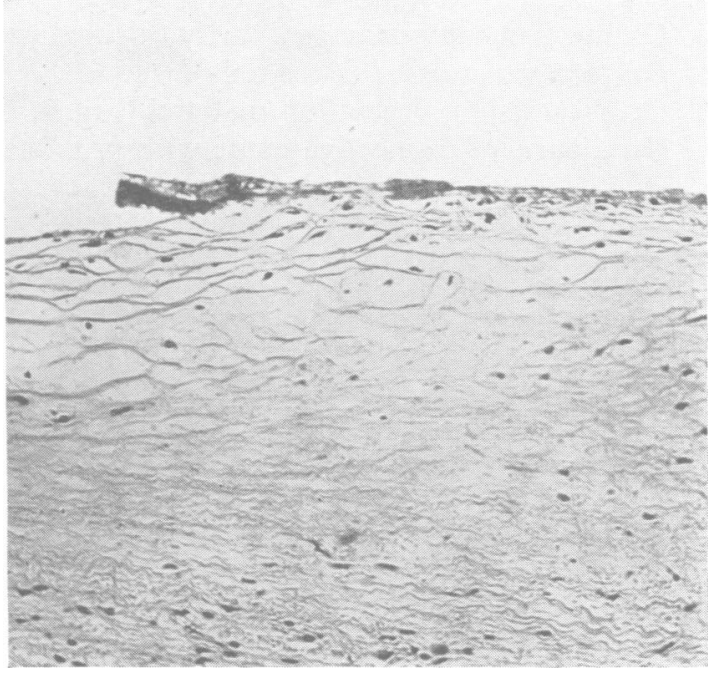

FIG. 10.-Tricuspid valve, showing superficial degenerative changes and fine deposit. Paraffin embedded section. ( $\mathrm{H}$ and $\mathrm{E}) \times 140$.

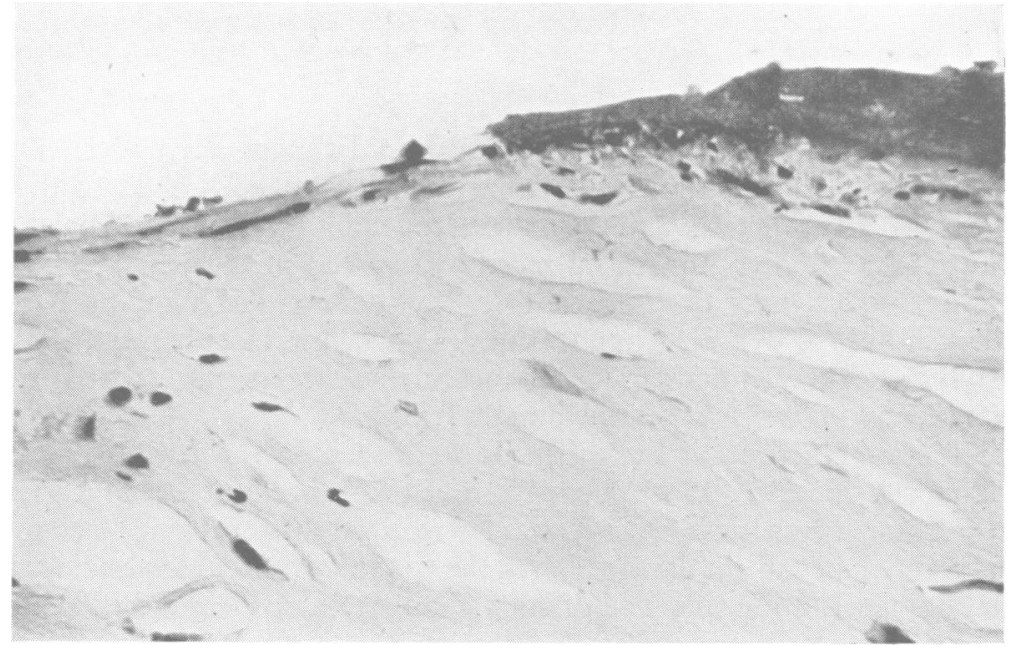

FIG. 11.- Recent deposit on mitral valve, showing pyknotic changes in underlying nuclei. Paraffin embedded section. (H and E) $\times 275$.

\section{The Changes Preceding Thrombus Deposition}

In the course of the investigation an attempt was made to determine what change immediately preceded vegetation formation. Fig. 4, 8, 10, 11, and 12 show the various conditions associated with the presence of recent deposit which was found on the following structures.

1. On degenerating endothelium (Fig. 10).

2. On collagenous tissue in which the surface layer of cells showed only minimal pyknotic changes (Fig. 11). 
3. On relatively acellular collagen denuded of endothelium (Fig. 12).

4. On mechanically damaged partly calcified collagen.

5. On torn valve tissue (once only).

6. On pre-existing vegetation material (Fig. 3, 4, 6, 7, and 8).

7. On a basis of connective tissue with proliferating fibroblasts.

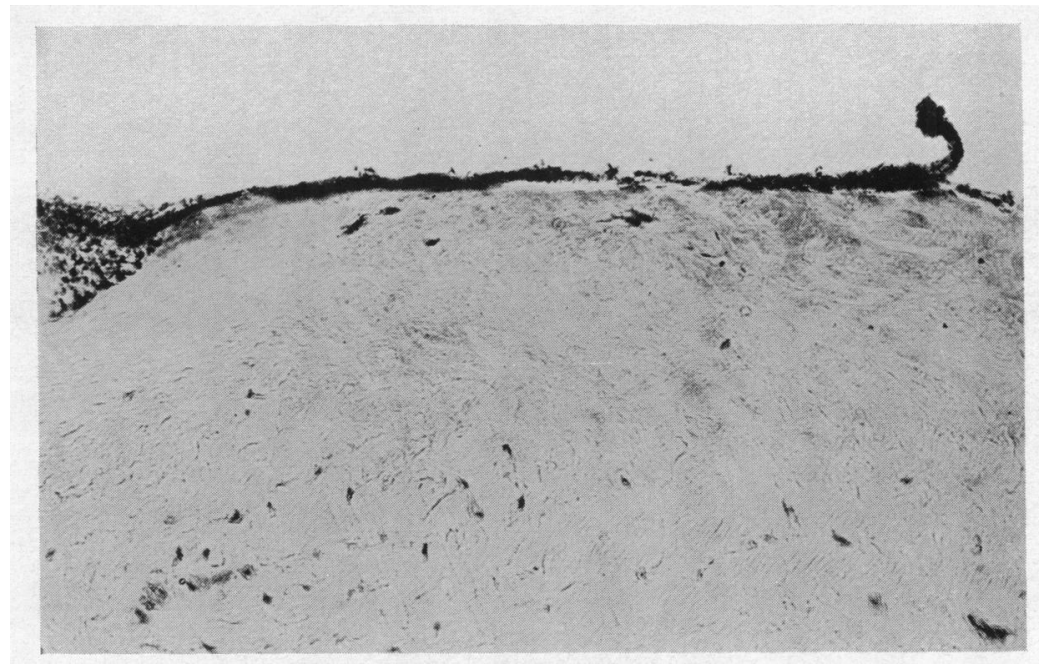

FIG. 12.-A deposit, partly fibrillary and partly condensed, on a valve cusp devoid of endothelium. Cellular "ghosts" are seen in underlying tissue. Frozen section. (Hæmatoxylin) $\times 40$.

In these photographs it can be seen that neither fibrinoid change nor underlying inflammation is necessarily present at the onset of thrombus deposition. Damage limited to the endothelium or absence of a well defined and differentiated normal endothelium seems to be sufficient to allow deposition. Although deposits are commoner and more widespread in the inflamed cusp, inflammatory changes, e.g. Aschoff nodes, may occur deep to a well defined endothelium without there being any thrombus deposition. Pyknotic changes may also occur in subendothelial tissues without evidence of overlying endothelial damage or of thrombosis necessarily occurring. Deposits were never seen on completely normal well-defined endothelium.

Sometimes pyknotic changes and karyorrhexis were seen in the endothelium (Fig. 10) or in the cells invading recent deposit. It was thought that this represented one of the essential lesions predisposing to thrombus deposition, but it was later realized that this sort of change occurs almost entirely at sites of severe mechanical damage. As the trauma of valve closure does not usually cause visible endothelial damage, the occurrence of such changes at closure sites indicates the action of a noxious agent in addition to the trauma itself.

\section{Discussion}

It has been shown that swollen acidophil material in a valve cusp is always explicable as incorporated thrombus. A problem that arises is whether the inflammatory changes necessarily precede thrombus deposition in the acute and subacute stages, or whether they merely accompany it or result from it. In the acute cases studied it was difficult to tell which was primary inflammation and which was the result of organization of repeated widespread thromboses. Inflammatory infiltration of cells such as polymorphs and plasma cells was slight; lymphocytes were moderately plentiful, but proliferation of fibroblasts was the main change. EEdema is difficult to diagnose unequivocally histologically and can be mimicked by the myxomatous appearance in organizing 
thrombi (Fig. 7). Many of the fibroblasts seen were large and deformed with many processes, the so-called Aschoff cells; they may be basophilic or amphophilic and multinucleated. They are commonly seen invading the base of vegetations and were present even in cases of long-standing disease with advanced changes. In some cusps Aschoff nodes themselves were seen away from the main areas of vegetation formation and also in tissue that appeared to be a recently organized warty vegetation. The cellular reaction that seems most characteristic of rheumatic valve disease is the presence of Aschoff cells. These cells are almost always present in relationship to organizing deposits and are found mainly in the immediate vicinity of the thrombus or burrowing into it. In lesions such as those shown in Fig. 4 and 8 they may only be present in ones and twos; they become more difficult to find in the older more thickened and less cellular valves. They are also found in the valve cusp Aschoff nodes and here are related to what appears to be fragmented connective tissue without fibrinoid change. These cells seem to occur as a reaction either to tissue damage or to thrombosis; there is no indication that they are ever the forerunners of thrombus deposition, rather do they follow it.

The effect of organization of successive thrombotic deposits especially when widespread as in the acute (i.e. cellular) stages, will be the production of fibroblastic proliferation with vascularization of the new-formed tissue and perivascular lymphocytic cuffing such as is seen around the new vessels formed in relation to organizing mural thrombi. On the surface of some warty vegetations when organization is nearly complete, fibroblasts take up a palisade appearance. This is one particular pattern taken up by organizing cells in a particular situation and not a primary event as Leary (1932) suggests, though necrosis of such recently organized tissue may occur if it is subjected to trauma. Whether it becomes necrosed because it is intensely proliferating or because of damage due to the disease process is uncertain.

It is difficult to see the above described inflammatory changes in rheumatic valvulitis as the precursor of thrombus deposition. It seems rather that thrombus deposition can be initiated by a very minimal lesion of the surface endothelium of the valve, which may damage the superficial layers of cells enough to cause those that are mechanically damaged, such as those on the closure line, to become necrotic. At the same time as deposition occurs there is a cellular reaction of fibroblasts and Aschoff cells. As these cells invade the thrombus, more thrombus is commonly laid down on the surface. New growth of capillaries and small round cell infiltration follow. (Thrombosis in these new-formed capillaries is very common in the acute phase.)

In considering the problem of the nature of the lesion that precedes thrombus deposition, one is hampered by the fact that the valve cusps are already so changed even in the earliest cases that it is impossible to distinguish normal valve tissue from newly added tissue. However, one striking feature is the frequency with which thrombus is seen on a basis of connective tissue containing proliferating fibroblasts with many, few, or no Aschoff cells. It is as though there were some reaction between the connective tissue and the surrounding blood leading to continuous deposition of material. Whether the underlying tissue is relatively acellular collagen or myxomatous-looking intensely-proliferating tissue containing developing capillaries does not seem to matter very much. It is possible that changes in the coagulability of the blood are more important than changes in the underlying valve. However, there must be some phenomenon occurring in the valve to explain the Aschoff node lesions and the fact that deposition occurs mainly on valves, albeit at other sites in the circulation as well. In addition to these there must be some explanation for the fact that deposits are more intense and more widespread on younger more acute valvular lesions. It is true that sometimes the size of individual vegetations is greater in old thickened rheumatic valves, but this is partly due to the fact that the valves are less cellular and thrombotic deposits are more slowly organized. It remains true that in rheumatic valve disease the lesion in the valve that leads to thrombosis is not usually histologically visible.

A suggested sequence of events in acute valvulitis is therefore: œdema, perhaps with Aschoff node formation, and relatively minor cellular infiltration-minimal damage to endothelium-widespread thrombus deposition-rapid organization with fibroblasts and Aschoff cells-further 
thrombosis-vascularization and perivascular lymphocytic infiltration. This scheme is instead of: cedema, sometimes cellular infiltration-proliferation of fibroblasts and capillaries-fibrinoid degeneration of collagen with swelling and overlying endothelial necrosis-thrombus deposition and organization.

In subacute and chronic lesions the differences are mainly those of degree; fibroblastic proliferation and vascularization become less intense, Aschoff cells less prominent, and fewer cells are involved in the conversion of thrombus to new connective tissue which is much more hyaline. Fig. 6, 8, and 11 show three stages of decreasing cellularity. The more hyaline tissue contains more fat and elastic laminæ may become very thick and sometimes have a granular appearance like the elastic tissue in Lambl's excrescences (Magarey, 1949). Although in the later stages the new-formed tissue is hyaline from the beginning, such tissue is of course also formed from connective tissue that was initially more cellular.

A remark must be made about old thickened valves where fragmentation of degenerate pale staining or calcifying collagen has formed a focus for thrombus deposition. Here the fragmentation, the avascularity and hypocellularity of the valve tissue may be the main factor in deposition. In common with more acute lesions there is the absence of endothelium.

It is impossible to say precisely what proportion of the thickening of valve cusps is due to deposited material. There are three ways in which the thickening may occur. (1) Cusps may be "blown up" as it were from within by imbibition of fluid or proliferation of cells throughout the valve or in parts of it, (2) they may be thickened from the surface by cells "piling up" on the free surfaces and growing out into the surrounding blood stream, or (3) material may be deposited on the surface and be organized. Sections have been seen that suggest the possibility of the second of these three mechanisms occurring; when plasma is caught up in pockets formed between cusps and chordæ and then coagulates, the growing processes of cells seem to be projecting into the coagulum. In the previous work reviewed, the "blowing up" effect was held to be the most important factor in thickening, until Magarey's paper. In support of the deposition theory it is significant that the greatest thickening of valve cusps is precisely at the place where vegetations are commonest, viz. on the free edge and the contact line. It must be remembered that the contact line of rheumatic valves is not a fixed point, but varies owing to factors that tend to lengthen and shorten the cusp. The tip itself comes to be made up entirely of added material and incorporated chordæ.

When it is considered that deposits can be found at almost all stages of rheumatic valvular disease if they are looked for carefully enough, that they may be very widespread, that the disease may go on for many years, and that individual lesions may take only a week or two to organize completely, it seems not unreasonable to suggest that a major part of the thickening that occurs is due to these deposits even though the other possible mechanism may also be involved in varying degree.

\section{SuMmary AND CONCLUSIONS}

The high incidence of thrombotic deposits on rheumatic valves is confirmed. They were found on valves at all stages of the disease, though there were fewer of them in the older lesions. They consist of fibrin and some other constituent, probably platelets.

The frequency of these deposits, their widespread nature in the acute stage, and the fact that all ages were often found in any one cusp support the hypothesis that they are responsible for much of the thickening in rheumatic valvular disease.

They are also thought to account for the mutual fusion of chordæ, for the fusion of chordæ to valve cusps, and for the incorporation of chordæ tendineæ into valve cusps.

In acute rheumatic valvulitis there is no certain method for distinguishing partially organized deposits from so-called fibrinoid degeneration of collagen; the idea of such degeneration may be a superfluous concept. These deposits are very widespread so that most of the actively proliferating tissue in these valves could well be due to the organization of successive thin deposits rather than a primary proliferation, especially as organization of a deposit often gives rise to a myxomatous 
appearance indistinguishable from an appearance of swelling due to œdema. It is likely that a large part of such myxomatous material in acute lesions is organized thrombus.

Neither valvulitis, in the sense of a primary proliferative lesion, nor a pre-existing degenerative lesion of collagen or ground substance is a necessary pre-requisite of thrombus deposition. This may occur when endothelial damage or absence appears to be the sole lesion.

Acknowledgment and thanks are due to Professor J. B. Duguid, who suggested the subject of this study, for his encouragement and help; to Dr. W. G. A. Swan and to Dr. C. D. Jobling for providing some of the material.

\section{REFERENCES}

Allen, A. C., and Sirota, J. H. (1944). Amer. J. Path., 20, 1025.

Altshuler, C. H., and Angevine, D. M. (1949). Amer. J. Path., 25, 1061.

Aschoff, L., and Tawara, S. (1906). Brit. med. J., 2, 1103.

Barnard, P. J. (1953). J. Path. Bact., 65, 129.

Brock, R. C. (1952). Brit. Heart J., 14, 489.

Bulloch, W. (1906). In A System of Medicine. Allbutt, T. C., and Rolleston, H. D., London, the Macmillan Company. Clawson, B. J. et al. (1926). Amer. J. Path., 2, 193.

Coombs, C. F. (1909). Quart. J. Med., 2, 26.

(1911). J. Path. Bact., 15, 489.

- (1924). Rheumatic Heart Disease. Bristol: John Wright \& Sons, Ltd.

Duguid, J. B. (1952). Lancet, 2, 207.

Grant, R. T., Wood, J. E., and Jones, T. D. (1927-29). Heart, 14, 147.

Gross, L., and Friedberg, C. K. (1936). Amer. J. Path., 12, 855.

Klinge, Fritz (1933). Der Rheumatismus. Ergeb. d. allg. Pathol. u. path. Anat., $27,11$.

Koletsky, S. (1946). Amer. J. Path., 22, 351.

Koniger, H. (1903). Histologische Untersuchungen der Endokarditis, Arb a.d. Path. Inst. zu Leipzig, S. Hirzel.

Leary, T. (1932). Arch. Path., 13, 1.

Magarey, F. R. (1949). J. Path. Bact., 61, 203. (1951). Brit. med. J., 1, 856.

Murphy, G. E. (1952) Histopathology of Rheumatic Fever. In Rheumatic Fever, Ed. L. Thomas, Minneapolis (p. 34).

Rindfleisch, E. (1872). A Manual of Pathological Histology. New Sydenham Soc., London, p. 288.

Rokitansky, C. (1852). A Manual of Pathological Anatomy, Vol. IV. Sydenham Soc., London, pp. 227 and 234.

Swift, H. F. (1925). Amer. J. med. Sci., 170, 631.

Tamayo, P., and Ihnen, M. (1953). Amer. J. Path., 29, 233.

Veraguth, O. (1895). Virchows Archiv, p. 59.

Wilson, M. G. (1940). Rheumatic Fever, New York.

Zucker, H. D. (1949). Blood, 4, 631. 